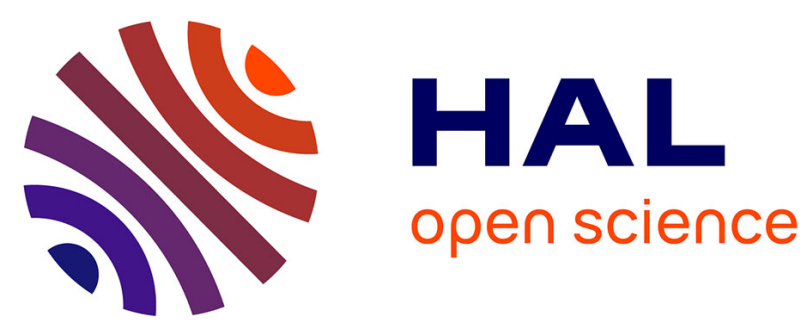

\title{
A Portable Sensor With Disposable Electrodes for Water Bacterial Quality Assessment
}

Marco Grossi, Roberto Lazzarini, Massimo Lanzoni, Anna Pompei, Diego Matteuzzi, Bruno Riccò

\section{- To cite this version:}

Marco Grossi, Roberto Lazzarini, Massimo Lanzoni, Anna Pompei, Diego Matteuzzi, et al.. A Portable Sensor With Disposable Electrodes for Water Bacterial Quality Assessment. IEEE Sensors Journal, 2013, 13 (5), pp.1775-1782. 10.1109/JSEN.2013.2243142 . hal-01276554

\section{HAL Id: hal-01276554 https://hal.science/hal-01276554}

Submitted on 25 Feb 2016

HAL is a multi-disciplinary open access archive for the deposit and dissemination of scientific research documents, whether they are published or not. The documents may come from teaching and research institutions in France or abroad, or from public or private research centers.
L'archive ouverte pluridisciplinaire HAL, est destinée au dépôt et à la diffusion de documents scientifiques de niveau recherche, publiés ou non, émanant des établissements d'enseignement et de recherche français ou étrangers, des laboratoires publics ou privés. 


\title{
A Portable Sensor with Disposable Electrodes for Water Bacterial Quality Assessment
}

\author{
Marco Grossi, Roberto Lazzarini, Massimo Lanzoni, Member, IEEE, Anna Pompei, Diego Matteuzzi \\ and Bruno Riccò, Fellow, IEEE
}

\begin{abstract}
Bacterial screening is very important in water environmental monitoring, since the presence of dangerous pathogens can seriously endanger human health. Microbial concentration detection is performed by Standard Plate Count technique, which is reliable but is characterized by long response time and is not suitable to be implemented in automatic form.

This work presents a portable sensor implemented as an electronic embedded system featuring disposable measurement cells and based on impedance measurements, that is suitable to measure bacterial concentration in water samples.

The system provides much faster response than standard technique $(3-12$ hours depending on the contamination level vs. 24 - 72 hours of the standard technique) and can be used for insitu microbial test without the need to ship samples to a laboratory for analysis.

Water samples from different sources (rivers, wastewaters, watercourses) have been tested using the presented system. Enriched medium has been added to the sample to favour bacterial growth. Three different media have been tested (Lauria Bertani, Mc Conkey Broth, Lactose Broth) and data have been compared in relation to microbial growth rate and selectivity towards bacterial group (e.g. coliforms).
\end{abstract}

The obtained experimental data showed good correlation with Plate Count technique.

Index Terms - portable sensor, embedded system, disposable electrodes, bacteria, impedance, coliforms.

\section{INTRODUCTION}

$\mathrm{T}_{\mathrm{r}}$ he detection of water contaminants is of primary importance in environmental monitoring since the presence of pathogens can seriously endanger human health [1]. This applies to drinking water as well as to river and seawater and wastewater.

Manuscript received June $29^{\text {th }}, 2012$. This work was supported in part by Spinner 2013 Program, funded by Regional Operation Program 2007-2013 (Emilia Romagna, Italy), Ministry of Labour, Health and Social Policy (Italy) and the European Social Fund (ESF).

M. Grossi, M. Lanzoni and B. Riccò are with the Department of Electronic Engineering (D.E.I.S.), University of Bologna, 40136 Bologna, Italy (e-mail: marco.grossi8@unibo.it massimo.lanzoni@unibo.it bruno.ricco@unibo.it).

R. Lazzarini is with Carpigiani Group, 40011 Anzola Emilia, Bologna, Italy (e-mail: robertolazzarini@ carpigiani.it).

A. Pompei and D. Matteuzzi are with the Department of Pharmaceutical Sciences, University of Bologna, 40126 Bologna, Italy (e-mail: pompeianna@hotmail.com diego.mat@teletu.it).
Drinking water must be bacterial free and, to guarantee this, it undergoes different sterilization processes [2] (such as chlorination) to eliminate dangerous bacterial concentration. However, contamination could occasionally occur after these treatments during the distribution process [3]: thus after each treatment step water microbial concentration must be regularly monitored.

Rivers and seawaters must also be screened for pathogens and, although microbial concentration limit is not as strict as in the case of drinking water, bacterial concentration should be low enough as to not represent a threat to human health.

Industry wastewaters must also be screened for pathogens since they end up in public waters and contribute to environmental contamination. This in particular applies to food industries, such as water used in meat treatment plants, where animal carcasses can seriously contaminate the water resulting from the process.

Water microbial screening is regulated by national and international regulations [4] and is aimed at detecting the presence of dangerous contaminants. Usually this is obtained by screening the sample for microorganisms that are related to faecal contamination since, from a statistical standpoint, these present a good correlation with the presence of pathogens. Traditionally, coliforms are considered the best indicators of faecal contamination [5]. In fact, even if not all coliform strains are pathogens, they primarily originate in the intestines of warm-blooded animals, hence they can be associated with faecal contamination. Nevertheless, there are many microorganisms (not belonging to the coliform group) commonly present in untreated water samples whose concentration largely exceeds that of coliforms. Under particular circumstances, some of these microorganisms (such as some genera of Pseudomonas and Flavobacterium) can represent a significant risk for human health.

In addition, high levels of total bacterial concentration indicate a reduction in water quality.

For these reasons, monitoring total bacterial concentration (in addition to coliforms concentration) can be a useful indicator of water quality.

Water microbial screening is normally carried out by Standard Plate Count (SPC) method [6], which is reliable and accurate but characterized by slow response ( $24-72$ hours) and must be performed by skilled personnel in microbiology 
laboratories, thus further delaying the measuring time due to the need to send the samples under test to a laboratory.

A set of instruments suitable for the detection of coliforms concentration in water samples are already present on the market, as those produced by IDEXX (Westbrook, Maine, USA): Colilert, Colilert 18 and Colisure [7][8]. Such systems use the detection technique named Defined Substrate Technology (DST), that is based on the coliforms property to produce $\beta$-glucuronidase as the result of their metabolism. Water samples are introduced in $100 \mathrm{ml}$ wells together with a dehydrated medium and are incubated at $37{ }^{\circ} \mathrm{C}$ for $18-22$ hours. At the end of the assay the number of wells whose color has turned yellow (signalling the presence of coliforms) or fluorescent yellow (because of the presence of Escherichia coli) is counted and the microbial concentration is inferred by statistical tables. The IDEXX instruments are laboratory oriented, their response time is only slightly shorter than SPC and color discrimination is eye based (in the case of fluorescence detection an UV lamp is required).

Research in environmental monitoring has developed many types of sensors for the screening of microorganisms [9][10][11] as well as for the detection of toxic pollutants in water [12][13]. Recently, the authors have proposed an embedded system that is highly competitive with SPC in terms of measuring time $(3-12$ hours depending on the sample contamination) and features user-friendly procedures, with no need of a laboratory environment, that allow its application for in-situ determination of bacterial concentration [14]. This system detects bacterial concentration in liquid and semi-liquid samples by using the impedance technique [15]. It works as follows. The Sample Under Test (SUT) is maintained at a constant temperature (generally in the range $30{ }^{\circ} \mathrm{C}-42{ }^{\circ} \mathrm{C}$ ) suitable for efficient bacterial growth. At regular intervals, the SUT electrical characteristics (i.e. the impedance as well as its resistive and reactive components) are measured and plotted as function of time. After a short time needed for the electrodeelectrolyte system to stabilize, measured electrical parameters remain essentially constant (baseline value) until a critical bacterial concentration (in the order of $10^{7} \mathrm{CFU} / \mathrm{ml}$ ) is reached. Then the SUT impedance modulus, as well as its components, begin to change significantly. Since the time needed for the electrical parameter to deviate from its baseline value, hereafter called Detect Time (DT), is linearly related to the logarithm of initial bacterial concentration, this value can easily be worked out.

The particular electrical parameter (i.e. resistive or reactive impedance component) used as monitor is essentially related to the SUT, whose chemical composition makes one impedance component more sensitive to bacterial growth than the other [16].

If the SUT doesn't contain enough nutrients to allow bacterial population to grow to the critical threshold of $10^{7}$ $\mathrm{CFU} / \mathrm{ml}$ in reasonable time (as is the case of water samples) an enriched medium must be added to the SUT. The choice of the proper medium is essential to guarantee a good trade off between bacterial growth rate and the growth medium selectivity towards a particular bacterial strain.

\section{MATERIALS AND METHODS}

An improved version of the portable system discussed in [14] has been used to monitor bacterial concentration of water samples taken from rivers, wastewaters and watercourses in the surroundings of Bologna (Italy).

\section{A. The embedded system}

The system is composed of two electronic boards: one for measuring the SUT electrical parameters (also suited for DT evaluation), while the other is a thermoregulation board controlling the SUT temperature with oscillations lower than $0.15^{\circ} \mathrm{C}$.

As discussed in [14] and [17], sample temperature must be maintained as stable as possible to avoid fluctuations of the electrical parameters that affect the measurement reliability. The SUT is placed in an incubation chamber featuring a couple of electrodes for electrical characterization and an heating system to maintain the sample to the target temperature. Two serial ports RS-232 provide the communication with an eeePC system for on-line monitoring of the assay, setting the assay parameters and data filing. Wireless data transfer can be done using a GT863-PY terminal by Telit and an Ethernet port for worldwide data transfer. A web application developed ad hoc allows data sharing with a hierarchical level of user privileges.

Fig. 1 (a) presents the schematic for the different parts of the system. When receiving the start signal, the impedance measurement board enables the thermoregulation board and waits 30 minutes for the SUT temperature to stabilize. Then, it measures the SUT electrical parameters at time intervals of 5 minutes. When the monitored electrical parameter deviates from its baseline value for more than $5 \%$ the assay ends and DT is calculated according to the algorithm presented in [14].

At test signal frequencies lower than $1 \mathrm{MHz}$, the electrodes-electrolyte system can be modeled as the series of a resistance $R_{s}$, accounting for the resistance of both the sample and the electrode-electrolyte interface and a capacitance $\mathrm{C}_{\mathrm{s}}$ (related to the formation of a double layer region at the electrode-electrolyte interface) [17].

The SUT electrical parameters have been measured using the electronic circuit (implemented in the system measurement board) represented in Fig. 1 (b). A sinusoidal voltage signal $\mathrm{V}_{\text {in }}(\mathrm{t})\left(100 \mathrm{mV}_{\mathrm{PP}} 200 \mathrm{~Hz}\right)$ is applied to the sensor electrodes and the current drawn $\mathrm{I}_{\text {in }}(\mathrm{t})$ is measured by means of a current to voltage (I/V) converter, whose output voltage $V_{\text {out }}(t)=-\left(R_{F} / Z_{s}\right) I_{\text {in }}(t)$ is linearly related with the current drawn by the sensor electrodes. Denoting with $\mathrm{V}_{\text {Min }}$, $\mathrm{V}_{\text {Mout }}$ and $\varphi$ the amplitudes of the signals $\mathrm{V}_{\text {in }}(\mathrm{t})$ and $\mathrm{V}_{\text {out }}(\mathrm{t})$ and the phase difference respectively, the SUT electrical 
(a)

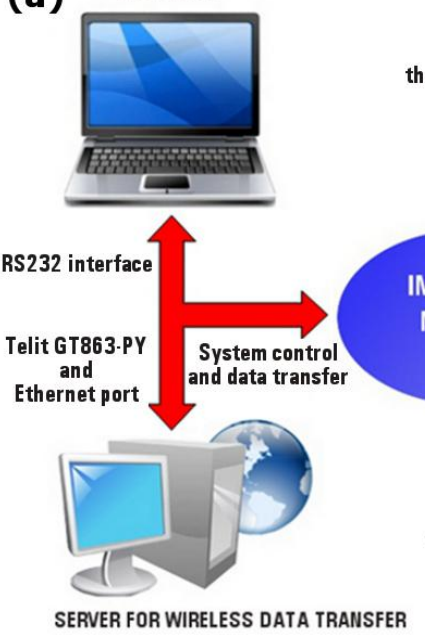

(b)

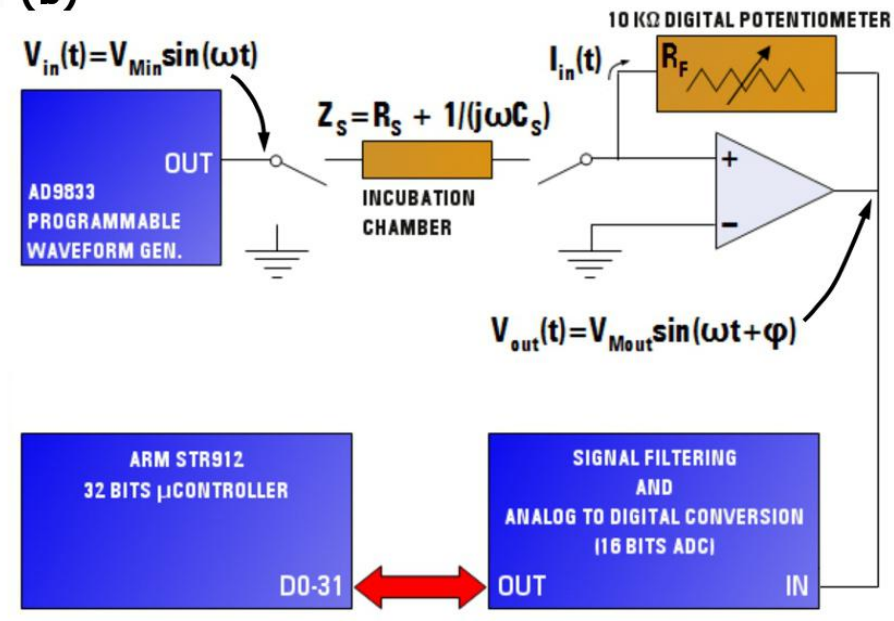

(c)
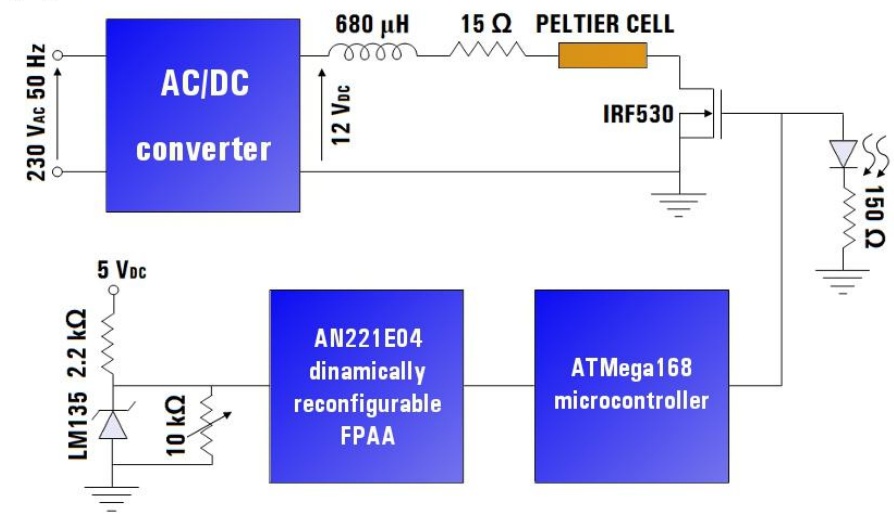

(d)

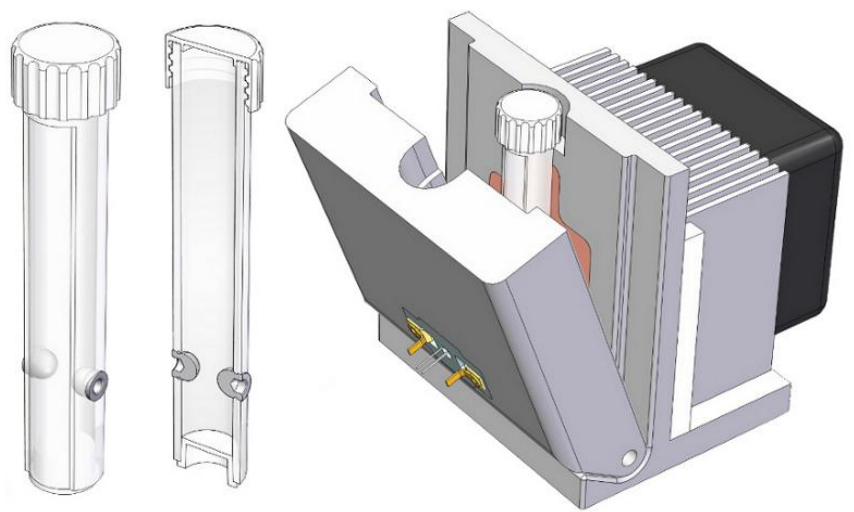

Fig. 1 Schematic representation of the sensor system (a), the circuit used to measure the sample electrical parameters (b), the thermoregulation circuit (c) and the incubation chamber (d).

parameters can be calculated using the aforementioned $\mathrm{RC}$ series model, producing the following formulas [16]:

$$
\begin{aligned}
& R_{s}=\left(V_{\text {Min }} / V_{\text {Mout }}\right) R_{F} \cos (\varphi) \\
& C_{s}=\left(1 / 2 \pi f R_{F}\right)\left(V_{\text {Mout }} / V_{\text {Min }}\right)(1 / \sin (\varphi))
\end{aligned}
$$

The voltage signals $\mathrm{V}_{\text {in }}(\mathrm{t})$ and $\mathrm{V}_{\text {out }}(\mathrm{t})$ are filtered (to remove high frequency and power line noise), converted into digital form and sent to ARM STR912 microcontroller for data processing.

The schematic of the thermoregulation board is presented in Fig. 1 (c). The sample temperature is measured with a LM135 (National Semiconductor, Santa Clara, USA) Zener diode with a breakdown voltage proportional to the absolute temperature and a slope $10 \mathrm{mV} /{ }^{\circ} \mathrm{K}$. The voltage from LM135 is filtered and amplified by the dynamically reconfigurable Field Programmable Analog Array (FPAA) AN221E04 (Anadigm, USA) and sent to the microcontroller ATMega168 (Atmel, California, USA) that calculates the sample temperature. The ATMega168 controls by PID algorithm the time period the n-channel power MOSFET IRF530 (Fairchild Semiconductor, USA) is turned on to supply a Peltier cell in the incubation chamber with a DC voltage of $12 \mathrm{~V}$.

\section{B. The incubation chamber}

The incubation chamber is the most critical part of the system. It must contain the sample in direct contact with the electrodes and maintain it at a constant temperature. At the beginning of each assay the chamber must be sterile so as to not contaminate the SUT and alter the assay results. Since at the end of the previous assay the sample in the chamber has reached a very high level of bacterial contamination $\left(>10^{7}\right.$ $\mathrm{CFU} / \mathrm{ml}$ ), the incubation chamber must undergo a sterilization process so as to eliminate the residual bacterial concentration. In the first implementation of the system [14], the sterilization process was performed by exposing the chamber to $100{ }^{\circ} \mathrm{C}$ steam flow for 10 minutes, a procedure that proved to be efficient for reliable measurements. Since, however, steam vapor sterilization is a complicate procedure that needs dedicated instruments and is difficult to implement for in-situ measurements, recently we have developed a disposable incubation chamber allowing to avoid sterilization before use.

The new incubation chamber is composed of: a) a permanent housing, featuring the temperature sensor, the 


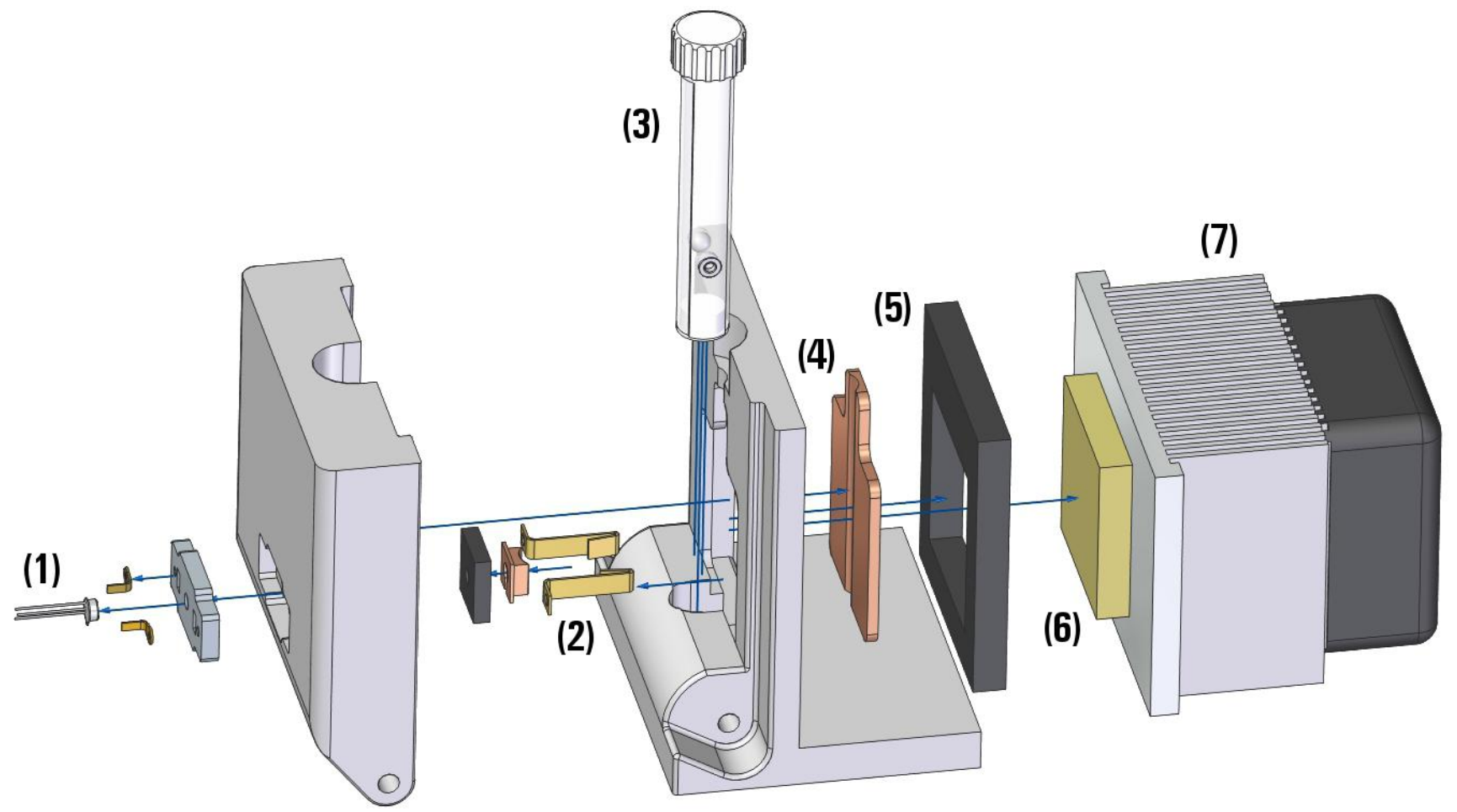

Fig. 2 Representation of the different parts of the incubation chamber: (1) LM135 temperature sensor, (2) sliding contacts for the disposable cell electrodes, (3) disposable cell, (4) thermal spreader, (5) thermal insulation, (6) Peltier cell, (7) fan operated heatsink.

heating system and all the interconnections to the electronic boards; b) a disposable cell (Fig. 1 (d)).

A representation of the different parts of the incubation chamber is shown in Fig. 2. The temperature sensor LM135 is placed in direct contact with the disposable cell to sense the SUT temperature and control the heating system accordingly. The Peltier cell (40 mm x $40 \mathrm{~mm}$ x $4 \mathrm{~mm}$ ) sets the sample to the target temperature. The disposable cell, hosting the SUT during the assay, features a cylindrical structure $(\mathrm{L} 7.9 \mathrm{~cm}, \mathrm{~W} 1.3 \mathrm{~cm})$ and a couple of cap shaped stainless steel electrodes (6 mm diameter, $4 \mathrm{~mm}$ spaced) that are connected to the housing by means of sliding contacts. The temperature of the disposable cell is due to thermal exchange with the housing. Before starting the assay, a new (sterile) sensor cell is filled with the SUT and it is inserted in the housing. At the end of the assay it is extracted and be disposed of.

\section{Chemicals and media}

The study has been carried out on real water samples taken from rivers, wastewaters and watercourses in the surrounding of Bologna (Italy) and stored at $4{ }^{\circ} \mathrm{C}$ for $24-$ 48 hours before use.

The tested samples have been diluted in enriched medium (ratio $1: 10$ ) to provide nutrients for bacterial growth. Three different enriched media have been tested: Lauria Bertani (modified to feature low salt concentration) for total bacterial concentration; Mc Conkey Broth and Lactose
Broth for coliforms concentration. The composition (for 1 liter of distilled water) for the three media is as follows. Lauria Bertani: Tryptone $10.0 \mathrm{~g}$, Yeast Extract $5.0 \mathrm{~g}(\mathrm{pH}$ 7.0). Mc Conkey Broth: Oxgall 5.0 g, Peptone 20.0 g, Lactose $10.0 \mathrm{~g}$, Bromcresol Purple $0.01 \mathrm{~g}$ (pH 7.3). Lactose Broth: Beef Extract $3.0 \mathrm{~g}$, Peptone $5.0 \mathrm{~g}$, Lactose $5.0 \mathrm{~g}$ (pH 6.9).

All the ingredients are purchased from Difco Laboratories (Detroit, USA). The incubation temperature has been set to $37^{\circ} \mathrm{C}$.

SPC measures of microbial concentration have been carried out immediately before the assay to test the correlation with the data obtained with the system of this work. Lauria Bertani agar has been used for total bacterial concentration and Mc Conkey agar for coliforms concentration.

\section{Statistical analisys}

Statistical analysis has been carried out on the experimental data using Microsoft Excel. Linear regression analysis has been used to estimate the relationship between measured DTs and logarithm of bacterial concentration determined by SPC. The regression line equation as well as the determination coefficient $\mathrm{R}^{2}$ have been calculated and the kinetics growth parameters for the bacterial population have been determined from the regression line equation. 

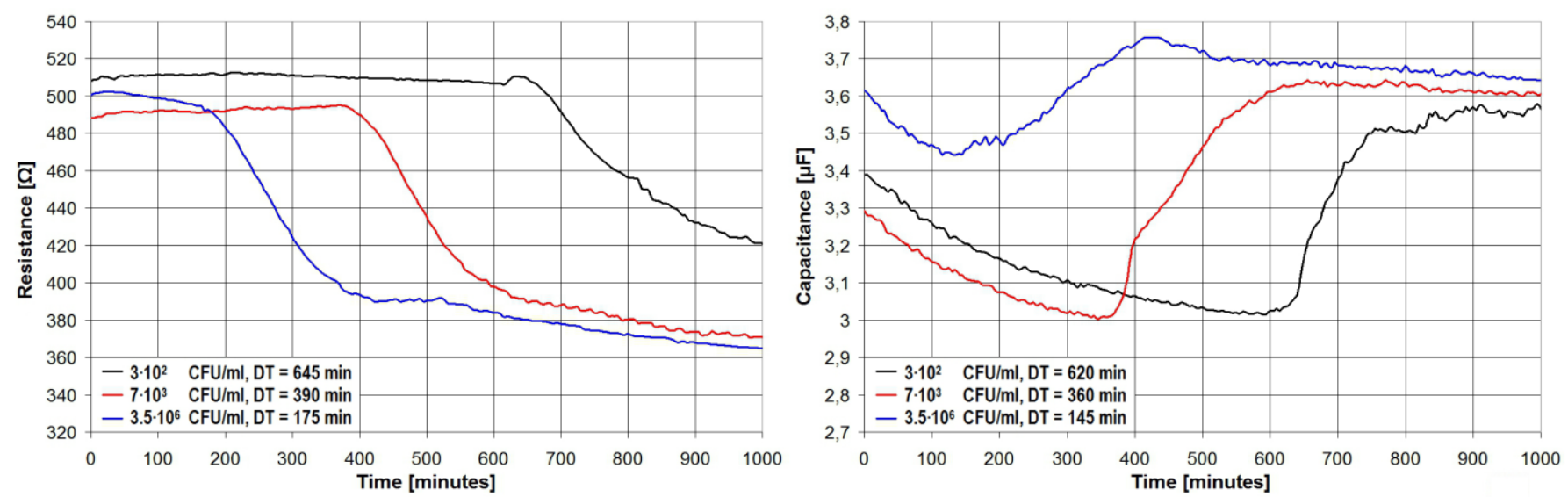

Fig. 3 Resistive and capacitive components of the impedance $Z_{s}$ vs. time for water samples characterized by different amounts of total bacterial contamination.

\section{RESULTS AND DISCUSSION}

Water samples have been tested using the system of this work and the results have been compared to the microbial concentrations measured by SPC.

The monitored curves for $\mathrm{R}_{\mathrm{s}}$ and $\mathrm{C}_{\mathrm{s}}$ (resistive and capacitive components of the impedance $Z_{\mathrm{s}}$, respectively) are shown in Fig. 3 vs. total microbial concentration in the case of samples diluted in Lauria Bertani medium in ratio $1: 10$.

As can be seen, lower contaminated samples are characterized by higher values of measured DT, while samples with high bacterial concentration feature low values for DT. With reference to Fig. 3, a bacterial concentration of $300 \mathrm{CFU} / \mathrm{ml}$ needs more than 10 hours to be detected while in the case of a strongly contaminated sample $\left(3.5 \cdot 10^{6}\right.$ $\mathrm{CFU} / \mathrm{ml}$ ) it takes less than 3 hours.

The choice of the enriched medium to dilute the water sample significantly affects the system performance (response time and accuracy), since the system detects the electrical changes in the medium due to bacterial metabolism. In general, large percent variations of the monitored parameter is desirable since this results in more reliable and accurate DT determination. Fig. 4 shows the percent change of $R_{s}$ and $C_{s}$ for all three enriched media (error bars indicate the dispersion, i.e. standard deviation): as can be seen the resistive component produces slightly larger variations than $\mathrm{C}_{\mathrm{s}}$ for all media but Mc Conkey medium, characterized by limited percent variations in $R_{s}$ due to the high bile salt concentration (Oxgall), partially masking the increased ion concentration by bacterial metabolism. The variation of $R_{s}$, instead, exhibits much lower dispersion than that of $\mathrm{C}_{\mathrm{s}}$. This can be related with the different physical causing the variation of the SUT electrical parameters. As bacterial population grows, microbial metabolism transforms uncharged particles in the medium in highly charged ones, thus modifying the ionic content of the SUT and increasing its bulk conductivity (hence $R_{s}$ decreases). The ions in the electrolyte are subjected to different electrical forces at the electrodes and in the bulk of the SUT, thus leading to the formation of a double layer region at the electrode-electrolyte interface (hence $\mathrm{C}_{\mathrm{s}}$ increases). This interface capacitance dominates the total impedance value at low frequency.

Fig. 5 shows coliforms bacterial concentration (measured by SPC in Mc Conkey agar) vs. total bacterial concentration

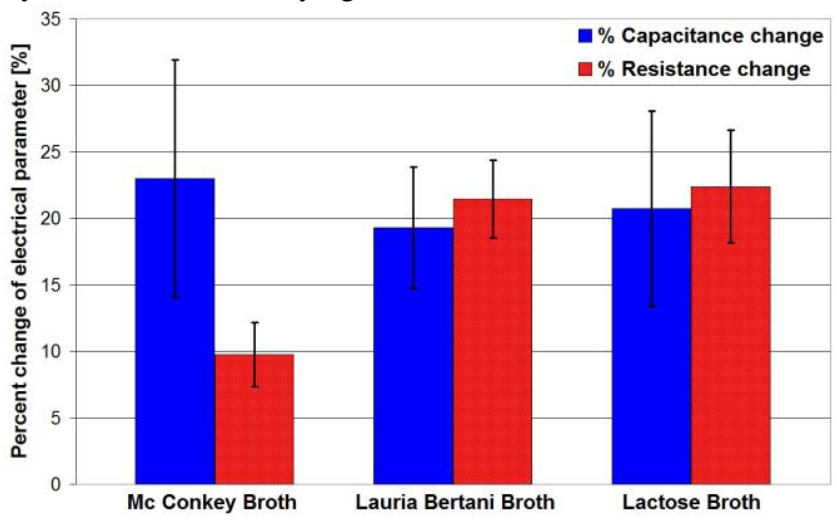

Fig. 4 Percent change of $R_{s}$ and $C_{s}$ due to bacterial methabolism for the three enriched media used to dilute the water sample.

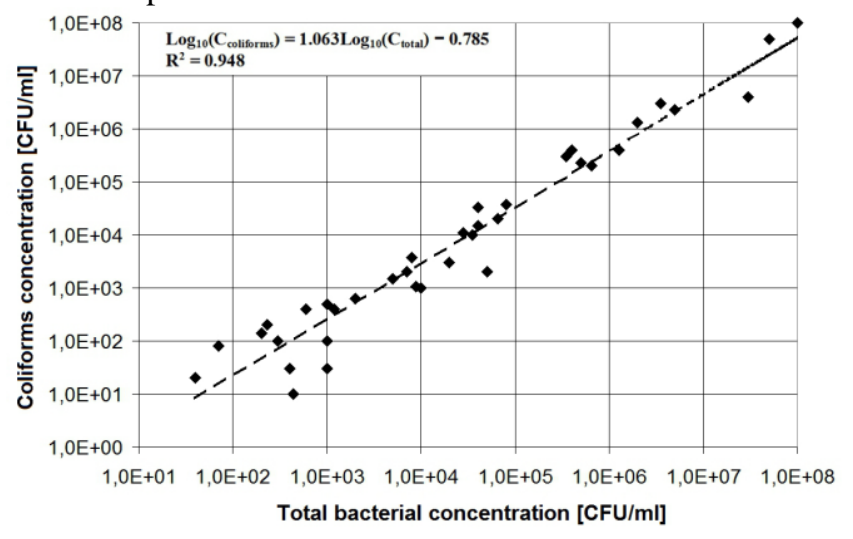

Fig. 5 Scatter plot of coliforms concentration vs. total bacterial concentration (measured by SPC). 

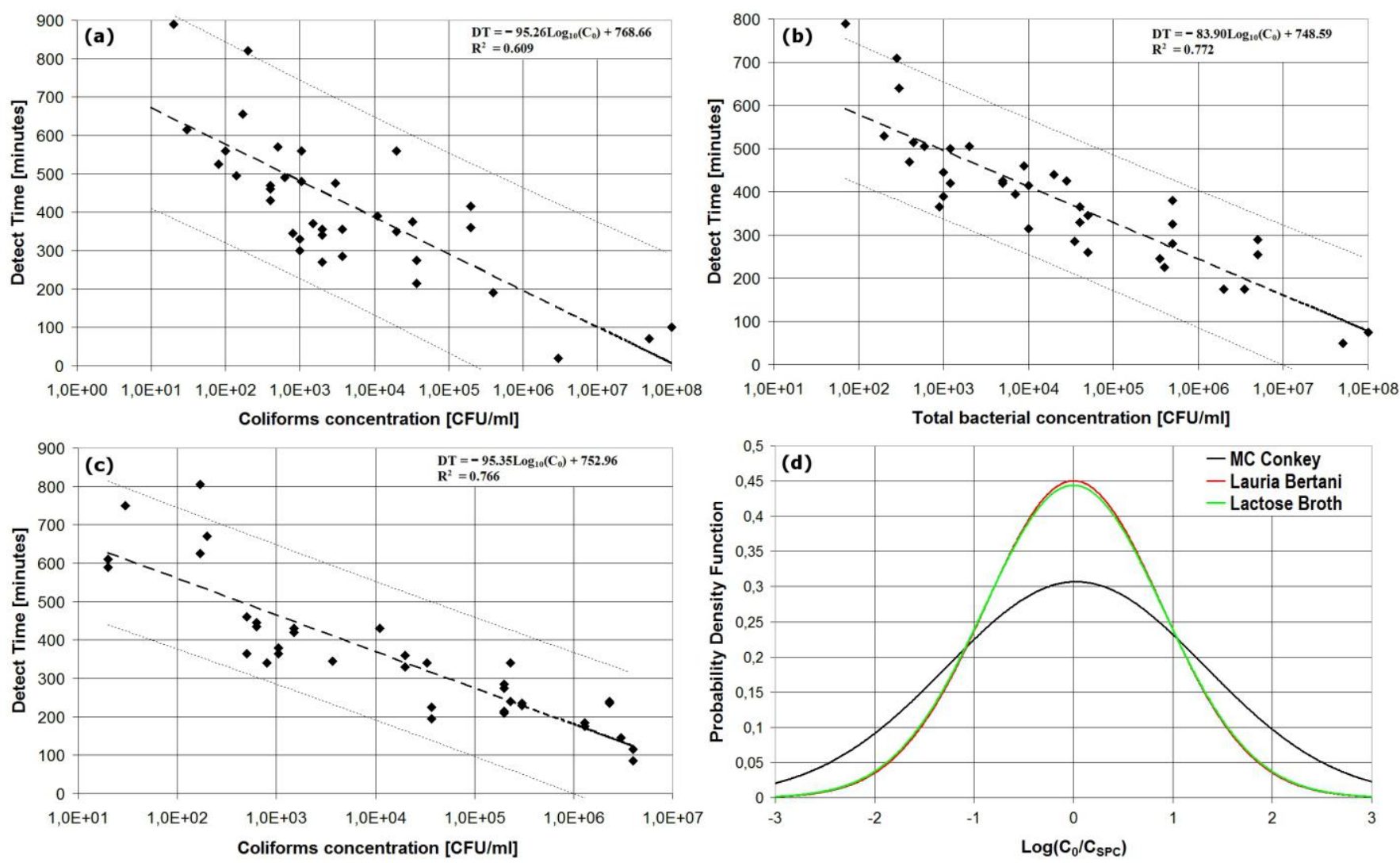

Fig. 6 Scatter plots of measured DT vs. microbial concentration for the three enriched media Mc Conkey Broth (a), Lauria Bertani (b) and Lactose Broth (c). Probability density function for the Gaussian variable $\log _{10}\left(C_{0} / C_{S P C}\right)$ for the three enriched media (d).

(measured by SPC in Lauria Bertani agar) for the entire set of water samples that have been tested. A linear relation exists between the logarithm of the two concentrations as pointed out in the figure inset, presenting both the linear regression line equation and the determination coefficient $\mathrm{R}^{2}$. The coliforms concentration in tested samples is about one order of magnitude lower than the total microbial concentration with good linearity between the two variables as indicated by the high value of the determination coefficient $\left(\mathrm{R}^{2}=0.948\right)$.

Water samples have been tested for all three enriched media and both electrical parameters. Fig. 6 (a), (b) and (c) show scatter plots (representing the measured DT vs. the logarithm of bacterial concentration determined by SPC) for the three enriched media in the case of DT calculated from $\mathrm{R}_{\mathrm{s}}$ plots (scatter plots from $\mathrm{C}_{\mathrm{s}}$ results in slightly higher dispersion, i.e. lower correlation between DT and bacterial concentration). In each figure the linear regression line equation, determination coefficient $\mathrm{R}^{2}$ as well as lower and higher bounds resulting from a Student t-distribution statistic with a confidence level of $95 \%$ are presented.

Lauria Bertani medium and Lactose Broth resulted in comparable accuracy with SPC (with values of $\mathrm{R}^{2}$ of 0.772 and 0.766 respectively) while the use of Mc Conkey medium produced lower correlation $\left(\mathrm{R}^{2}=0.609\right)$.
Based on the linear regression line equation, the estimated value of bacterial concentration $\mathrm{C}_{0}$ has been calculated. Since the statistical distribution for the random variable $\log _{10}\left(C_{0} / C_{S P C}\right)$ is known to be Gaussian [17], this has been assumed to calculate the distribution mean value and standard deviation. Fig. 6 (d) shows probability density functions of the random variable $\log _{10}\left(C_{0} / C_{S P C}\right)$. As can be seen Lauria Bertani medium and Lactose Broth are characterized by almost identical distributions while the Mc Conkey broth distribution (featuring significant higher value of standard deviation) results in wider dispersion for the estimated bacterial concentration.

Repeatability tests have been carried out on a limited number of samples to study the uncertainty in DT determination. The same sample has been tested with three different assays and the DT standard deviation $\sigma$ recorded. The results show that for Lauria Bertani medium $\sigma$ is 10.2 minutes, for Lactose Broth is 7.06 minutes while, in the case of Mc Conkey broth, is 32.9 minutes. As a comparison, the corresponding standard deviation for the whole set of water samples is 113 minutes for Mc Conkey broth, 42.98 minutes for Lauria Bertani medium and 46.63 minutes for Lactose Broth. This suggests that dispersion in scatter plots 


\begin{tabular}{ccccccc}
\hline \hline & \multicolumn{3}{c}{ Parameters measured from the resistance curves } & \multicolumn{3}{c}{ Parameters measured from the capacitance curves } \\
\hline Enriched medium & $\boldsymbol{T}_{\boldsymbol{G}}(\boldsymbol{m i n})$ & $\boldsymbol{T}_{\text {lag }}(\boldsymbol{m i n})$ & $\boldsymbol{R}^{2}$ & $\boldsymbol{T}_{\boldsymbol{G}}(\boldsymbol{m i n})$ & $\boldsymbol{T}_{\text {lag }}(\boldsymbol{m i n})$ & $\boldsymbol{R}^{2}$ \\
Mc Conkey Broth & $28.78 \pm 7.73$ & $103.27 \pm 95.77$ & 0.609 & $26.64 \pm 6.87$ & $73.83 \pm 85.11$ & 0.614 \\
Lauria Bertani & $25.18 \pm 4.76$ & $160.96 \pm 48.41$ & 0.772 & $26.18 \pm 5.18$ & $122.23 \pm 52.68$ & 0.750 \\
Lactose Broth & $28.39 \pm 5.53$ & $89.59 \pm 61.73$ & 0.766 & $29.33 \pm 6.05$ & $75.80 \pm 67.64$ & 0.728 \\
\hline \hline
\end{tabular}

Table 1 Estimated values of $T_{G}, T_{\text {lag }}$ and $R^{2}$ for the three enriched media. Results obtained monitoring the resistive and capacitive components of the impedance are shown.

of Fig. 6 is mainly due to differences in the growth speed of the different bacterial strains.

The scatter plot data of Fig. 6 can be used to analyze the dynamics of bacterial growth. As pointed out in [17], one can assume the linear regression equation $D T=A \times \log _{10}\left(C_{0}\right)+B$, where $\mathrm{C}_{0}$ is the initial unknown bacterial concentration, and denote: $\mathrm{T}_{\mathrm{G}}$ the mean generation time (i.e. mean time between cell duplication); $\mathrm{T}_{\text {lag }}$ the lag time needed for the microbial strains to adapt themselves to growth conditions; $\mathrm{C}_{\mathrm{T}}$ the critical threshold concentration of $10^{7} \mathrm{CFU} / \mathrm{ml}$ and $\tau$ the 30 minutes time delay for the sample temperature to stabilize. Then, it is:

$C_{T}=C_{0} \times 2^{\left(D T+\tau-T_{\text {lag }}\right) / T_{G}}$

Comparing Eq. (3) with the linear regression equation it is:

$T_{G}=-A \times \log _{10}(2)$

$T_{\text {lag }}=B+\tau+A \times \log _{10}\left(C_{T}\right)$

Statistical analysis has been carried out to test if any significant difference exist for the regression line parameters in the cases of the three enriched media (with a confidence level of 95\%). The obtained results indicate that no significant differences exist in the intercept $\mathrm{B}$ of the regression lines for the different enriched media, while media used for selective coliforms detection (Mc Conkey and Lactose Broth) are caracterized by significantly higher values of the slope A than in the case of Lauria Bertani.

Table 1 presents the estimated values for $\mathrm{T}_{\mathrm{G}}, \mathrm{T}_{\text {lag }}$ and $\mathrm{R}^{2}$ for the three enriched media as obtained with both the resistive and capacitive component of the impedance.

\section{CONCLUSIONS}

An embedded portable sensor system featuring a disposable measurement cell has been presented. The system is particularly suitable for in-situ detection of bacterial concentration in water samples and is competitive with the standard technique in terms of time response (312 hours vs. $24-72$ hours) and possibility to be implemented in automatic form.

The system has been used to test the microbial concentration in water samples from different sources (rivers, wastewaters, watercourses), that have been diluted in a suitable enriched medium. Three different media have been tested and the system response has shown good correlation with the standard technique (in particular for the enriched media Lactose Broth and Lauria Bertani). By using the appropriate enriched medium either coliforms or total bacterial concentration can be reliably estimated with response time as low as 3 hours for highly contaminated samples $\left(>10^{6} \mathrm{CFU} / \mathrm{ml}\right)$. Furthermore, diluting the water samples in specific enriched medium the determination can be made selective for different types of bacteria.

On the whole, the obtained result indicates that the presented system is a reliable tool for fast and in-situ water monitoring.

\section{REFERENCES}

[1] J.L. Liang, E.J. Dziuban, G.F. Craun, V. Hill, M.R. Moore, R.J. Gelting, R.L. Calderon, M.J. Beach and S.L. Roy, "Surveillance for waterborne diseases and outbreaks associated with drinking water and water not intended for drinking - United States 2003-2004", Surveillance Summaries, vol. 55 (SS12), pp. 31-58, 2006.

[2] G.A. Boorman, V. Dellarco, J.K. Dunnick, R.E. Chapin, S. Hunter and F. Hauchman, "Drinking water disinfection byproducts: review and approach to toxicity evaluation", Environmental Health Perspectives, vol. 107, no. 1, pp. 207-217, 1999.

[3] E.J. Lee and K.J. Schwab, "Deficiencies in drinking water distribution systems in developing countries", Journal of Water and Health, vol. 3, no. 2, pp. 109-127, 2005.

[4] R.A. Corbitt, Standard handbook of environmental engineering, McGraw-Hill Publishing Co. ( ${ }^{\text {nd }}$ edition), New York, 1990.

[5] A. Romprè, P. Servais, J. Baudart, M.-R. de-Roubin and P. Laurent, "Detection and enumeration of coliforms in drinking water: current methods and emerging approaches", Journal of Microbiological Methods, vol. 49, pp. 31-54, 2002.

[6] C.W. Kaspar and C. Tartera, Methods in microbiology, Grigorova \& J.R. Norris ed., London : Academic Press, 1990, vol. 22, pp. 497531.

[7] J.K. Cowbum, T. Goodall, E.J. Fricker, K.S. Walter and C.R. Fricker, "Preliminary study on the use of Colilert for water quality monitoring", Letters in Applied Microbiology, vol. 19, no. 1, pp. 50$52,1994$.

[8] K.-K. Chao, C.-C. Chao and W.-L. Chao, "Evaluation of Colilert-18 for detection of coliforms and Escherichia coli in subtropical freshwater", Applied and Environmental Microbiology, vol. 70, no. 2, pp. 1242-1244, 2004.

[9] P. Leonard, S. Hearty, J. Brennan, L. Dunne, J. Quinn, T. Chakraborty and R. O'Kennedy, "Advances in biosensors for detection of pathogens in food and water", Enzyme and Microbial Technology, vol. 32, pp. 3-13, 2003.

[10] Y.Y. Goh, B. Ho and J.L. Ding, "A novel fluorescent protein-based biosensor for gram-negative bacteria", Applied and Environmental Microbiology, vol. 68, no. 12, pp. 6343-6352, 2002.

[11] S.A. Chiappini, D.J. Kormes, M.C. Bonetto, N. Sacco and E. Cortòn, "A new microbial biosensor for organic water pollution based on measurement of carbon dioxide production", Sensors and Actuators B : Chemical, vol. 148, pp. 103-109, 2010.

[12] H. Chapman and Y.A. Owusu, "Rapid, state-of-the-art techniques for the detection of toxic chemical adulterants in water systems", IEEE Sensors Journal, vol. 8, no. 3, pp. 203-209, 2008. 
[13] A.A. Ensafi, S. Meghdadi and E. Fooladgar, "Development of a new selective optical sensor for $\mathrm{Cd}(\mathrm{II})$ ions based on 4-hydroxy salophen", IEEE Sensors Journal, vol. 8, no. 11, pp. 1794-1800, 2008.

[14] M. Grossi, M. Lanzoni, A. Pompei, R. Lazzarini, D. Matteuzzi and B. Riccò, "An embedded portable biosensor system for bacterial concentration detection", Biosensors and Bioelectronics, vol. 26, pp. 983-990, 2010.

[15] R. Firstemberg-Eden and G. Eden, Impedance microbiology, Wiley : New York, 1984, vol. 3, pp. 154-196.

[16] M. Grossi, M. Lanzoni, A. Pompei, R. Lazzarini, D. Matteuzzi and B. Riccò, "Detection of microbial concentration in ice-cream using the impedance technique", Biosensors and Bioelectronics, vol. 23, pp. 1616-1623, 2008.

[17] M. Grossi, A. Pompei, M. Lanzoni, R. Lazzarini, D. Matteuzzi and B. Riccò, "Total bacterial count in soft-frozen dairy products by impedance biosensor system", IEEE Sensors Journal, vol. 9, no. 10, pp. 1270-1276, 2009.

Marco Grossi received the degree in electronic engineering from the University of Bologna, in 2000 and the Ph. D. degree in 2004. He is currently involved in projects of innovative sensors for bacterial detection in food products and the characterization of food samples by electrical impedance spectroscopy.

Roberto Lazzarini graduated in Nuclear Engineering from the University of Bologna. He has broad international experience in the Food Equipment sector and is (co-) author of publications and several international patents. $\mathrm{He}$ is now Head of Research and Development in Carpigiani Group.

Massimo Lanzoni (M'87) received the degree in electronic engineering from the University of Bologna in 1987. He is Associate Professor of Electronics since 2001 and is involved in projects concerning sensor design, characterization and development of virtual instruments and sensors for biological applications.

Anna Pompei received the degree in biology and the Ph.D. degree from the University of Bologna, Bologna, Italy, in 2000 and 2006, respectively. She is currently involved in the research of innovative techniques in hygiene quality control for bacterial detection in food products, isolation and characterization of microorganisms to employ in functional food.

Diego Matteuzzi is a Full Professor of Industrial Microbiology at the Department of Pharmaceutical Science, from the University of Bologna, Bologna, Italy, since 1981.

Bruno Riccò (SM'91-F'03) in 1971 graduated in electrical engineering at the University of Bologna (Italy); in 1975 received a Ph.D. from the University of Cambridge (U.K.) where he worked at the Cavendish Laboratory; in 1980 became Full Professor of Electronics at the University of Padua (Italy) and in 1983 at the University of Bologna (Italy); in the period 1981 - 1986 he was Visiting Professor at the University of Stanford, at the IBM Thomas J. Watson Research Center (Yorktown Heights) and at the University of Washington; from 1986 to 1996 was European Editor of the IEEE Transaction on Electron Devices; in 1995 received the G. Marconi Award for research by the Italian Association of Electrical and Electronics Engineers (AEI); 1998 became President of the Italian Group of Electronics Engineers; in 1999 was appointed European representative for the International Electron Device Meeting (IEDM); in 1999 founded the first university spin-off in Italy; in 2002 he has been elected Chairman of the IEEE North Italy Section; in 2003 was nominated Fellow of the IEEE. Prof. Riccò has worked in the field of microelectronics and is (co-) author of over 400 publications, more than half published on major international Journals, of 3 books and several international patents. 